\title{
Uma Retórica primordial: de Górgias de Leontini à projeção discursiva dos Black Blocs
}

\section{A primordial rhetoric: from Górgias of Leontini to discursive projection of Black Blocs}

Melliandro Mendes Galinari

UFOP

melliandro@yahoo.it

Gabriela Nascimento Rossi de Oliveira

UFOP

gabriela_rossi_1@yahoo.com.br

Resumo: Este artigo apresenta uma definição de Retórica a partir da obra de Górgias de Leontini, um dos mais importantes sofistas em atividade na Atenas do século V a.C. Além disso, busca demonstrar a influência de suas reflexões no pensamento de Friedrich Nietzsche para, em seguida, conectá-las à Análise Argumentativa do Discurso, tal como postulada por Ruth Amossy. Esse percurso teórico tem como objetivo resgatar uma concepção alternativa do processo argumentativo, não o reduzindo ao mapeamento exaustivo de técnicas conscientes ou tipos de argumento, como fazem algumas perspectivas herdeiras da vertente aristotélica e perelmaniana. Assim, tem-se como problema central a busca por uma definição de Retórica cada vez mais compatível com a abordagem de todo e qualquer mecanismo da estrutura da linguagem (modalizações, estruturas narrativas, ritmo etc.), o que ultrapassa a observação de tipologias de argumentos de caráter lógico ou quase-lógico. Como 
resultado teórico, mostra-se que a Retórica está ligada, primordialmente, à não transparência e à opacidade do discurso, o que implica em associála ao fato de a linguagem, em toda a sua estrutura material, não coincidir com o real. Para colocar em prática as reflexões teóricas desenvolvidas, o artigo faz uma sucinta análise de uma reportagem presente em uma revista brasileira (Revista Época), cujo tema é a atuação dos Black Blocs nas manifestações que tomaram as ruas do Brasil a partir de junho de 2013. Palavras-chave: Retórica; Análise do Discurso; Sofística; Górgias de Leontini; Black Blocs.

Abstract: This article presents a definition of rhetoric by Gorgias of Leontini, one of Athens most important active Sophists of the $5^{\text {th }}$ Century BC. Moreover, it aims to demonstrate the influence of his reflections on Friedrich Nietzsche's philosophy, which will subsequently be connected to the Argumentative Discourse Analysis, postulated by Ruth Amossy. This research aims to revisit this alternative discussion of an argumentation process, not reducing it to repetitive definitions of techniques and argument types, as some approaches related to Aristotelianism or the Perelmanian Philosophy do. Thus, the main question is to find a definition of Rhetoric more compatible to the approach of language structure mechanisms (modality, narrative structures, rhythm, etc.), something more wider than the arguments of logical or almost logical nature. As a theoretical result, it is shown that Rhetoric is linked, primarily, to nontransparency and opacity of speech, which leads to the association that language, in all its material structure, is not equal to reality. To put into practice the developed theoretical concept, this research presents a brief analysis of an article published in the Brazilian magazine Época, about the actions of Black Blocs during the protests in the streets of Brazil since June 2013.

Keywords: Rhetoric; Discourse Analysis; Sophistry; Gorgias of Leontini; Black Blocs.

Recebido em 10 de julho de 2015. Aprovado em 28 de março de 2016. 


\section{Introdução}

Atualmente, no campo da Análise do Discurso (AD), quando se buscam estudos e definições sobre a Retórica (ou argumentação), diversas formulações apresentam-se confortavelmente ao pesquisador, por serem já bastante disseminadas e absorvidas por essa área de pesquisa. Sabese, assim, que a Retórica é "a capacidade de descobrir o que é adequado a cada caso com o fim de persuadir" (ARISTÓTELES, 1998, p. 28), ou, até mesmo, um ato singular, relacionado ao "estudo das técnicas discursivas permitindo provocar ou aumentar a adesão das mentes às teses que se apresentam ao seu assentimento" (PERELMAN; OLBRECHTSTYTECA, 2002, p. 50). A partir de definições desse tipo (dominantes), técnicas e/ou tipologias de argumentos são correntemente elencadas no intuito de apreender o que seria a argumentação (ou a Retórica), com o objetivo de instrumentalizar essas categorias no campo da AD.

O analista, assim, depara-se, frequentemente, com argumentos já codificados e à espera de uma aplicação prática diante de variados corpora. Além da trilogia logos/ethos/pathos, sistematizada em Aristóteles (1998), encontramos à nossa disposição uma exaustiva listagem de terminologias em diversos livros, tratados ou manuais, como o entimema (dedução) e o exemplo (indução). Em tempos modernos, Perelman e Olbrechts-Tyteca (2002) nos fornecem, por exemplo, um elenco ainda mais complexo: (i) os argumentos quase-lógicos (contradição, incompatibilidade, identidade, definição, transitividade, comparação, inclusão, divisão, probabilidade); (ii) os baseados na estrutura do real (por sucessão, por coexistência); (iii) os que fundamentam a estrutura do real (o exemplo, a ilustração); e (iv) os argumentos por dissociação.

Listagens, definições e categorizações desse tipo têm cristalizado um hábito investigativo nada incomum nos tempos atuais, o que muitas vezes torna difícil ao leitor a compreensão do campo, dado o enxame terminológico e as derrapagens de significado de autor(a) para autor(a). Apenas para citar dois exemplos já bastante conhecidos no âmbito dos Estudos da Linguagem (embora de vertentes teóricas distintas), podemos nos referir à Teoria da Argumentação na Língua, de Anscombre e Ducrot (1983), e à Teoria Semiolinguística de Charaudeau (2009).

No primeiro caso, a argumentação é vista como a passagem de um enunciado E1, com valor de argumento, a um enunciado $\mathbf{E 2}$, com valor conclusivo. Nesse sentido, a argumentação se vê remodelada como 
uma "semântica ideal da frase", isto é, como uma possibilidade de se encadear enunciados na sequência do discurso, o que a figura como uma capacidade da língua de gerar, por sua força interna, certas conclusões na superfície textual. A teoria de Ducrot e Anscombre é conhecida, hoje, por extrair da argumentação o seu elemento contextual e controverso - a persuasão -, dado que esse fenômeno é considerado como uma propriedade intrínseca à estrutura da língua em detrimento dos sujeitos que a utilizam. No contexto discursivo da Teoria Semiolinguística, por sua vez, a argumentação se transforma em um "modo (específico) de organização do discurso", posto como distinto de outras estruturas, ou seja, dos chamados modos narrativo, descritivo e enunciativo. Em um viés logicizante, portanto, a argumentação se encontra, aqui, atrelada ao que o autor denomina "modos de encadeamento" (causa, consequência, conjunção, disjunção) e aos já conhecidos "modos de raciocínio" (dedução, explicação, associação etc.) (CHARAUDEAU, 2009, p. 201-249)

Essa trama teórica de sistematizações logicizantes, como sabemos, não termina por aqui: basta lembrarmos as diversas teorias lógico-normativas (como a Lógica Informal e a Pragma-Dialética) e suas listagens exaustivas de falácias e/ou paralogismos, além do tratamento da argumentação (por correntes da Linguística Textual) como uma "sequência linguística" dentre outras, tais como a narrativa, a injuntiva, a preditiva, a descritiva etc. Trata-se de áreas bastante diversas, mas que, explícita ou implicitamente, não hesitam em rotular a argumentação (ou a Retórica) como razões mais ou menos conscientes destinadas a conduzir um auditório para certas teses ou conclusões, encaminhando-nos para a listagem e aprendizagem de "técnicas", "operações mentais" ou "raciocínios prototípicos", articulados e caracterizados por conectores textuais de várias ordens (mas, portanto, porque, e, além de etc.).

Diante desse vasto quadro, o problema que motiva este artigo é saber se não existiriam outras perspectivas possíveis de (entre)olhar a Retórica, passíveis de se conectar à $\mathrm{AD}$ atual e à sua concepção não transparente de linguagem, escapando-se, ao mesmo tempo, do que poderíamos chamar de um furor terminológico logicizante. Dessa forma, sem desconsiderar o legado aristotélico e outras vertentes já bastante conhecidas, como as apontadas sumariamente acima, gostaríamos de apresentar aqui o que pensamos ser uma concepção primordial de Retórica. Tal postulado tem como base as reflexões sofísticas de Górgias de Leontini, pensador em atividade na Atenas democrática de Péricles, 
no século V a.C. Embora vários pesquisadores no campo da História e da Filosofia tenham já resgatado a Sofística como um todo, de modo a ressaltar a sua importância retórica/filosófica (desde pelo menos o final do século XIX), acreditamos que a AD moderna ainda não tirou proveito significativo de tal legado ${ }^{1}$.

Sendo assim, buscaremos a seguir, num primeiro momento, resgatar a Retórica sofística de Górgias a partir de sua obra intitulada Tratado do não-ente ou Da natureza, preservada nos escritos de Sexto Empírico (apud SOUSA; PINTO, 2005). Diante desse resgate, pretendemos trazer, rapidamente, a contribuição de Nietzsche (2000) para a referida questão - um conhecido leitor dos sofistas -, associando essas reflexões à noção moderna de dimensão argumentativa, desenvolvida por Amossy $(2010,2011)$ no quadro atual da AD. Nossa hipótese, que buscaremos demonstrar, é que a Retórica, antes de ser uma técnica ou um conjunto de especulações presentes em diversos tratados ou manuais, configura-se, em seus primórdios, como a propriedade de a linguagem inteira (muito além de raciocínios ou tipos de argumento) não coincidir com a estrutura do real, dada a sua opacidade e não transparência.

Num segundo momento, o artigo coloca essas reflexões em prática a partir da análise da reportagem intitulada "Por dentro da máscara dos Black Blocs" (ROCHA, 2013), publicada pela Revista Época em 11 de novembro de 2013. Nosso intuito, com a análise, é apenas ilustrar as especulações teóricas

\footnotetext{
${ }^{1}$ São vários os trabalhos e estudos contemporâneos que resgatam o valor filosófico e educativo dos sofistas, livrando-os do preconceito platônico-aristotélico que os consagrou como enganadores, mercenários ou sujeitos que do conhecimento detinham apenas a aparência. Como exemplo, podemos citar: Untersteiner (2012), Casertano (2010), Vignali (2006), Pinto (2000), Romilly (1988), Romeyer-Dherbey (1986) e Saitta (1938), entre outros. Como se sabe, o conhecimento produzido pelos sofistas desapareceu quase totalmente. $\mathrm{O}$ que nos restam são apenas alguns fragmentos e, principalmente, testemunhos como os de Diógenes Laércio, Sexto Empírico, Platão, Aristóteles e tantos outros que citam e discutem as questões colocadas pelos sofistas. Felizmente, hoje, contamos com autores que reuniram em uma só obra esses fragmentos e testemunhos antigos a partir do grego e do latim. Os primeiros foram Diels e Kranz, que os traduziram para o alemão na obra Die Fragmente der Vorsokratiker. Algum tempo depois, o italiano Untersteiner (1967) fez o mesmo em seu idioma, porém com uma edição mais completa e aperfeiçoada (I Sofisti: testimonianze e framenti). Sousa e Pinto (2005), por sua vez, publicaram uma versão em português a partir dos trabalhos anteriores, a qual utilizaremos neste artigo.
} 
já desenvolvidas, buscando apreender, no contexto pós-manifestações de junho de 2013 (no Brasil), como os ditos manifestantes Black Blocs foram projetados retoricamente por parte da grande imprensa nacional.

O ano de 2013, como se sabe, foi descrito por vários jornalistas e movimentos sociais como um marco para a sociedade brasileira no âmbito político (MARICATO et al., 2013). No início de junho daquele ano, inúmeras manifestações populares ocorreram para contestar o aumento das tarifas de transporte público nas principais capitais do Brasil, com o apoio de boa parte da população. No bojo dessas mobilizações, protestos se proliferaram em diversas cidades abrangendo vários temas, como os gastos públicos em eventos esportivos internacionais (a Copa das Confederações e a Copa do Mundo), a má qualidade dos serviços públicos e a corrupção política em geral. Nesse contexto, vimos surgir e proliferar na imprensa a expressão "Black Blocs", pouco conhecida no Brasil até então, referindo-se aos manifestantes ditos "violentos" e/ou "mascarados". O fenômeno despertou nosso interesse em cogitar sobre o funcionamento retórico da disseminação repentina dessa expressão em escala nacional, a partir do modo como esses manifestantes foram representados, o que servirá, como já dito, para ilustrar as reflexões teóricas desenvolvidas a seguir. Sendo assim, por ora passamos ao referido resgate da Retórica a partir da Sofística gorgiana.

\section{A Retórica de Górgias e as projeções do logos}

Antes de resgatar a Retórica gorgiana, torna-se oportuno esboçar, primeiramente, alguns princípios dos chamados filósofos pré-socráticos, que delinearam, ainda que indiretamente, uma concepção de linguagem hoje conhecida como "verifuncional", sagrada por uma busca contínua pela arché, isto é, por uma "verdade" sobre a estrutura e a organização do universo (cosmos). Tal esboço se mostra pertinente porque a Sofística (centrada no nomos) só pode ser entendida em contraposição às doutrinas de seus antecessores (centradas na physis). Atualmente, sabe-se que alguns pensadores pré-socráticos, conhecidos como physiólogoi (ou "naturalistas"), tinham como bússola investigativa o desvelamento do mundo e da natureza, como Tales de Mileto, Heráclito de Éfeso, Pitágoras, Parmênides, entre outros.

A complexidade e a convergência de tais pensadores para uma concepção transparente da linguagem (a-retórica) podem ser percebidas 
na leitura que Pinto (2000) faz de Heráclito e Parmênides. Mesmo tendo esses personagens especulado por vias distintas, ambos alçavam a linguagem à condição de traduzir fielmente o mundo fenomênico (a physis), seja este encarado como uma realidade estática, imutável ou homogênea (Parmênides), seja como algo em constante transformação ou contrariedade (Heráclito). Quanto à filosofia de Górgias, interessa-nos especificamente, aqui, o pensamento de Parmênides desenvolvido no quadro da chamada Escola Eleata, uma vez que seus princípios foram diretamente refutados pelo sofista.

$\mathrm{O}$ único fragmento parmenidiano que sobreviveu aos tempos é um poema intitulado Sobre a natureza (PARMÊNIDES, 2013). Em sua trama, um ilustre narrador confidencia, alegoricamente, uma genuína façanha em busca do conhecimento: uma viagem de "carro" impulsionada por um par de éguas, conduzidas pelas filhas do sol (as Helíades). O caminho pelo qual é transportado, distante do caminho usual dos mortais, é a via da noite e a via do dia. Num itinerário pelo cosmos, o viajante chega a um enorme portal de pedra, protegido por sua guardiã: Dice, a deusa da Justiça. As filhas do sol persuadem-na, e ela abre a porta para que o navegante passe, transportado pelos corcéis. O narrador, enfim, é recebido pela deusa, cujo discurso configura o restante do poema. Dice o informa, assim, eloquentemente, que não fora enviado por um destino funesto, mas pela Lei e pela Justiça:

Ó Jovem, acompanhante de aurigas imortais,

tu, que chegas até nós transportado pelos corcéis,

Salve! Não foi um mau destino que te induziu a viajar

por este caminho - tão fora do trilho dos homens -, mas o Direito e a Justiça. Terás, pois, de tudo aprender:

o coração inabalável da verdade fidedigna

e as crenças dos mortais, em que não há confiança genuína (Ibid., p. 14)

No fragmento 1, a deusa apresenta ao viajante as duas vias possíveis de investigação do conhecimento. A primeira é a "via da verdade", do discurso fiável e fidedigno, associado ao Direito e à Justiça Divina. A segunda é a "via da opinião", isto é, das crenças dos mortais perdidas no trilho ilusório dos homens. No fragmento 2 , a deusa então prossegue: 


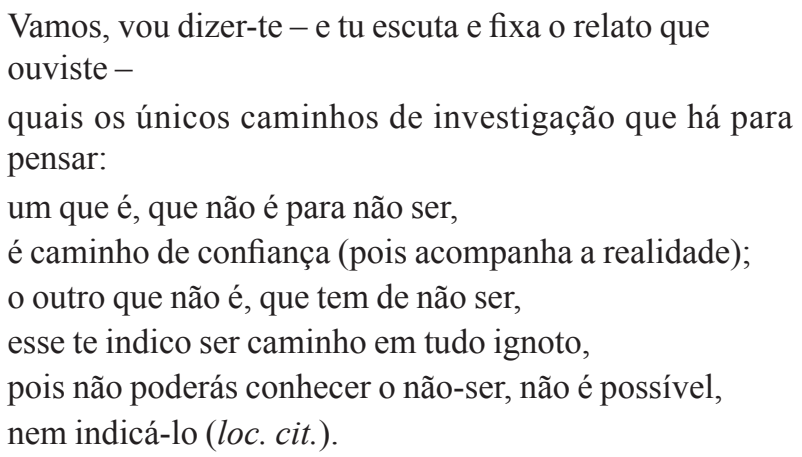

Como se vê, a via da verdade é a via confiável, posto que acompanha a realidade, associando-se ao ser, isto é, àquilo que é, ou àquilo que existe fidedignamente. A via da opinião, por sua vez, é completamente impraticável ("caminho ignoto"), visto que aquilo que não é (o não-ser, o inexistente) não se pode conhecer, expressar ou ser dito. $\mathrm{O}$ poema de Parmênides, por tal especulação, é conhecido por inaugurar a epistemologia ocidental - a teoria sobre o conhecimento -, uma vez que instaura uma oposição entre a opinião (doxa) e a Ciência (episteme), em sua busca incessante pelo "dizer verdadeiro". Para tanto, o poema conta com uma crença imprescindível, que irradia como pressuposto: a crença na capacidade da linguagem (ou logos) de atingir as coisas tais e quais elas são, ou seja, o conhecido postulado da transparência do discurso, construído por um processo de maturação racional e abstrato. Nas palavras da deusa, "é necessário que o ser, o dizer e o pensar sejam; pois podem ser, enquanto o nada não é: nisto te indico que reflitas" (Ibid., p. 15).

Parmênides formula, assim, uma visão muito particular sobre a filosofia ao desconsiderar os elementos sensoriais e os sentidos. Para ele, as sensações e os sentimentos não devem ser considerados numa investigação, pois suscitariam contradições e confusões entre o ser e o não-ser, o existente e o inexistente, como podemos notar, mais uma vez, no trecho a seguir (fragmentos 7-8):

pois nunca isto será demonstrado: que são as coisas que não são;

mas afasta desta via de investigação o pensamento, não te force por este caminho o costume muito experimentado, 
deixando vaguear olhos que não veem, ouvidos soantes e língua, mas decide pela razão a prova muito disputada de que falei (loc. cit.)

Nota-se, claramente, a construção de uma oposição central entre a "razão" (abstrata) e os sentidos ("olhos", "ouvidos", "língua"). Para o poema, portanto, aqueles que são levados pelas sensações acreditam que o ser e o não-ser são o mesmo, expediente característico dos mortais (que "nada sabem"). É nesse sentido que a sua linha de pensamento se desenvolve a partir de uma importante dicotomia - o caminho da opinião (doxa) versus o caminho da verdade (alétheia) -, paradigma muito caro ao pensamento Eleata. Para Galinari,

na ótica parmenidiana, só poderíamos dizer e pensar aquilo que existe ('o Ser'), ou melhor, aquilo que é, sendo impossível pensarmos aquilo que não é, ou seja, aquilo que inexiste (o 'não ser'), salvo quando erramos e adentramos no mundo perigoso das aparências. A verdade, assim, além de ligar-se à pensabilidade do Ser e à não-pensabilidade do não-ser, é concebida como una, indivisível, imutável ou, em outros termos, universal. (GALINARI, 2015, p. 96).

Pode-se dizer, assim, que já havia no mundo antigo, mesmo que indiretamente, uma concepção de linguagem capaz de representar plenamente as coisas (o Ser), tal e qual estas se encontrariam no mundo, uma vez que Parmênides associa o dizer verdadeiro ao dizer o que é, em essência. Sem entrar aqui em maiores detalhes, o que nos interessa é perceber, justamente, o fato de a linguagem, assim concebida, excluir a retórica, uma vez que é atribuída às coisas, eventos e fatos do mundo uma suposta essência, isto é, uma representação única e infalível. Em suma, aquém de qualquer controvérsia ou possíveis diferenças de pontos de vista, motivadas por fatores culturais e dóxicos, haveria uma "verdade" a ser espelhada pelo logos, alcançável, por um lado, por um processo de maturação racional e, por outro, pela expulsão das sensações para o campo das aparências ou da mera opinião.

Após Parmênides e outros pensadores buscarem a verdade através da physis, alguns sofistas, como Górgias de Leontini, deram lugar a outro polo de reflexão-o nomos -, por perceberem a necessidade de reconhecer 
e analisar o contexto cultural e os contratos sociais estabelecidos no universo de produção dos discursos (GUTHRIE, 1995). O eixo de pensamento por trás da terminologia nomos ("convenção/cultura"), em oposição à physis ("natureza"), está intimamente ligado às atividades dos sofistas após 460 a.C., momento em que Atenas vivia seu fervor democrático sob o comando de Péricles. O termo paulatinamente nos mostra que os fatos e os constituintes do mundo não possuem uma essência ou uma verdade absoluta. Pelo contrário, as coisas são encaradas como projeções (possivelmente variadas) do logos, formatadas pela interferência de parâmetros culturais, elementos dóxicos e convenções instituídas socialmente.

É nesse momento, da lenta passagem de um regime oligárquico para um regime democrático, que as especulações filosóficas se deslocam da compreensão da "vida natural" (physis) para o entendimento dos "hábitos" do próprio homem em sociedade (nomos), o que era perfeitamente compatível com a figura do sofista, demandado por aquela conjuntura (democrática) para educar o indivíduo para a palavra pública. É por esse motivo, isto é, pelo foco no homem em detrimento da cosmologia, que muitos teóricos afirmam, atualmente, que os sofistas foram os responsáveis pela instauração de um verdadeiro pensamento antropológico-humanístico no mundo antigo ${ }^{2}$. Cabe lembrar que esses pensadores - a maioria estrangeiros em Atenas - viajavam por diversos lugares e, por isso, carregavam na bagagem um profundo conhecimento de diferentes culturas e costumes. Tinham sensibilidade, portanto, para perceber que todas as coisas e questões naturais/sociais eram determinadas/concebidas pelas ações e decisões humanas, em razão de valores e representações de mundo contraditórias, não havendo, nessa perspectiva, uma "natureza" monolítica ou uma "verdade" única. A noção de nomos representa, portanto, o eixo retórico-especulativo em que prevalecem as máximas culturais e as convenções sociais na definição $\mathrm{da}(\mathrm{s})$ verdade(s) - o primeiro conceito de cultura -, a exemplo das leis escritas, da moral, da religião e da política.

\footnotetext{
${ }^{2}$ Os historiadores dividem habitualmente a filosofia grega em três períodos: "o período cosmológico, que vai de cerca de 600 a.C. a cerca de 450 a.C.; o período antropológico (prático) que preenche a segunda metade do século V, aproximadamente (450 a.C.400 a.C.), e o período sistemático, que contém o desenvolvimento dos três grandes sistemas da ciência grega, os de Demócrito, de Platão e de Aristóteles (400 a.C.-322 a.C.)" (WINDELBAND, 1958, p. 119).
} 
É somente nessa conjuntura que podemos compreender as definições de Górgias acerca da linguagem, presentes em seu texto conhecido como o Tratado do não-ente ou da natureza, em que as teses de Parmênides, apontadas anteriormente, são desconstruídas uma a uma $^{3}$. O Tratado aparenta ter como objetivo demonstrar que a defesa de uma ontologia, universo de todos os filósofos naturalistas, é tarefa vã e humanamente impossível. Como bem nos afirma Adrados, "Górgias, em seu Tratado sobre o não-ser, demonstra os problemas entre o ser e o pensamento, entre o pensamento e sua expressabilidade em palavras" (ADRADOS, 1975 apud BRAZIL, 2012, p. 49). Ademais,

o Tratado gorgiano constitui-se assumidamente como um voraz ataque ao eleatismo - especialmente ao defendido pelo mestre desta escola, Parmênides. Para atestar este fato, basta percebermos que o texto de Górgias possui uma estrutura interna de desenvolvimento de argumentos que procura atacar o grande poema que o filósofo de Eleia escreveu, intitulado Tratado sobre o ser ou sobre a natureza, cujas teses centrais eram: o ser é, e o não ser não é; de onde se deduz, segundo Parmênides, que pensar e ser são a mesma coisa (BRAZIL, 2012, p. 49).

A postura antieleata de Górgias já é apresentada no primeiro parágrafo de seu Tratado do não-ente, a partir da enumeração de três teses centrais que são desenvolvidas ao longo do texto, a saber:

- Nada existe;

- Se algo existe, não é apreensível ao homem;

- Se é apreensível é, sem dúvida, intransmissível e inexplicável a outrem. (GÓRGIAS apud SOUSA e PINTO, 2005, p. 113)

Para Galinari,

a primeira tese - nada existe - reforça a descrença do sofista quanto à existência essencial de algo, das coisas mundanas,

\footnotetext{
${ }^{3}$ Pode-se inclusive perceber que o título do texto gorgiano, por si só, já retoma em antítese o título do Poema de Parmênides.
} 
enquanto possuidoras de uma natureza una, coerente e indivisível, ou ainda enquanto possuidoras de uma verdade monolítica e intrínseca à sua realidade fenomênica. Nesse sentido, para Górgias, nem o Ser, nem o não-ser parmenidianos, existiriam ontológica e metafisicamente falando, dado que tanto o que existe (o Ser), como o que não existe (o não-ser), seriam construções do $\log o s$ e do pensamento humano (GALINARI, 2015, p. 96)

Dito de outra forma, se algo é posto como existente (de alguma maneira e não de outra), ou se não é (ou seja, é figurado como inexistente), tudo não passaria de projeções do discurso afetadas pela doxa (valores) e por convenções de ordem cultural (nomos), princípio que fomentou uma visão antinaturalista da "realidade". Passando à segunda tese, o sofista nos diz que, mesmo se algo existisse, as coisas seriam incognoscíveis. Isso porque, de acordo com Galinari,

a natureza do $\log o s$, a sua estrutura lógica e linguística interior, não corresponde à suposta natureza das coisas, muito embora, tragicamente, utilizemos o logos para nos relacionarmos com o mundo. Nesse sentido, contrariando Parmênides, para Górgias não só é possível dizer e pensar o Ser (aquilo que é), como também o não-ser (aquilo que não é). Prova disso, ou seja, da pensabilidade das coisas inexistentes, é a nossa capacidade de imaginar, por exemplo, homens com asas, carros a voar sobre o mar, ou entidades como Sila e Quimera (GALINARI, 2015, p. 97).

Logo, o que vemos e ouvimos existe (ou não) porque é representado, embora a representação do ser não nos proporcione o ser em sua plenitude, sendo também possível, consequentemente, projetar o que não existe. Tomamos conhecimento de algo pela percepção e comunicamo-lo pela linguagem, o que torna a apreensão humana das coisas, tais e quais elas seriam essencialmente, algo impossível. Esses princípios são arrematados pelo sofista em sua terceira tese, já apontada e introduzida (como é habitual em sua linguagem) por um raciocínio concessivo/hipotético: "se [a coisa em si] é apreensível é, sem dúvida, intransmissível e inexplicável a outrem”. Nesse caso, vale a pena citar as próprias palavras de Górgias, presentes no testemunho de Sexto Empírico: 
Se, com efeito, as coisas existentes são visíveis, audíveis e, em geral, perceptíveis (o que significa que são substâncias exteriores), e destas as visíveis são apreendidas com a vista e as audíveis com o ouvido e não inversamente, como poderiam estas coisas ser reveladas a outrem? O meio por que as exprimimos é a palavra, e a palavra não é nem os fundamentos das coisas nem as coisas existentes. Em suma, não revelamos aos que nos rodeiam as coisas existentes, mas a palavra, que é outra relativamente aos fundamentos das coisas. Do mesmo modo que o visível não se pode tornar audível e vice-versa, assim o existente, porque tem um fundamento exterior, não se pode tornar a nossa palavra (GÓRGIAS apud SOUSA; PINTO, 2005, p. 117).

O que interessa ressaltar aqui é o surgimento de uma concepção não transparente de linguagem, esboçada em franca oposição aos pressupostos do poema de Parmênides. A Retórica, nessa perspectiva - este é o ponto a que queríamos chegar -, antes de ser uma técnica consciente, antes de se tornar um tratado com codificações, definições ou especulações ilustradas pela listagem de tipos de argumento ou raciocínio ${ }^{4}$, é consagrada como a propriedade geral (e mor) de toda a linguagem, já concebida, na antiguidade, como uma estrutura atravessada pelo equívoco. Isso significa que a persuasão se encontra, primordialmente, na apregoada não coincidência entre as palavras e as coisas, nos inevitáveis deslizes/ derrapagens entre significado e significante. Esses deslizes, fomentados pela interferência de valores (doxa) e por padrões culturais (nomos), denunciam a condição humana de projetar a "realidade" de forma "distorcida", conforme visões de mundo, afetos e interesses. Pode-se dizer, portanto, que a Retórica relaciona-se, antes de qualquer coisa, à nossa incapacidade (trágica) de atingirmos um mundo essencial, sendo toda verdade uma verdade retórica. Assim, a argumentação já estaria nos equívocos do discurso, em sua opacidade constitutiva ${ }^{5}$.

São esses fundamentos que levaram Nietzsche, em pleno século XIX, a sustentar, de certa forma, que a Retórica reside no inconsciente da linguagem, ou seja, na força arrebatadora do logos, sendo capaz de

${ }^{4}$ Como o entimema (dedução), o exemplo (indução), a associação, a dissociação etc. ${ }^{5}$ Como apontaremos em outro momento, com base em Amossy $(2010,2011)$, não distinguimos, aqui, os termos "Retórica" e "Argumentação" como se faz usualmente. 
demolir, até mesmo, a oposição parmenidiana entre doxa e episteme. Vejamos:

\begin{abstract}
Nunca se capta la esencia plena de las cosas. Nuestras expresiones verbales nunca esperan a que nuestra percepción y nuestra experiencia nos hayan procurado un conocimiento exhaustivo, y de cualquier modo respetable, sobre la cosa. Se producen inmediatamente cuando la excitación es percibida. En vez de la cosa, la sensación sólo capta una señal (Merkmal). Este es el primer punto de vista: el lenguaje es retórica, pues sólo pretende

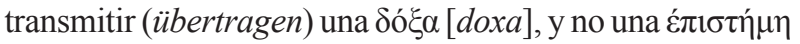
[episteme]·(NIETZSCHE, 2000, p. 91)
\end{abstract}

O que seria, pois, a Retórica, esse poder de persuasão? Nietzsche, um voraz leitor dos sofistas, nos leva a constatar que se trata do olhar aculturado, corporalizado e psicologizado do homem em relação ao universo: um mundo inatingível que lhe escorre entre os dedos. Ao depararmos com a "coisa em si", produzimos, inicialmente, uma "excitação nervosa" balizada por valores e afetos, já em si não coincidente com o "real". Por sua vez, essa sensação se transmuta em imagens subjetivas, em significados e significantes, em cópias de sensações que, ao serem verbalizadas, nos afastam ainda mais de qualquer conhecimento respeitável sobre qualquer coisa, não escapando desses deslocamentos nem mesmo o inabalável conhecimento científico (episteme). Nesse jogo de transposições e afastamentos, a Retórica se reencontra no sutil desencontro (inconsciente) entre as palavras e as coisas: uma Retórica primordial pautada no equívoco e na opacidade da linguagem.

Essas reflexões, acreditamos, abrem caminhos para a apreensão da força argumentativa dos discursos para além do mapeamento mecânico de tipos de raciocínio ou operações mentais, ou seja, das conhecidas técnicas conscientes, uma vez que a linguagem inteira é retórica. Nesse sentido, as categorias que modernamente chamamos, nos campos da Linguística, por exemplo, de modalizadores, marcadores de polifonia, elementos de referenciação, indicadores prosódicos etc., podem ser o ponto de partida (ou o centro) de uma abordagem argumentativa no campo da AD. Entretanto, ao dizermos, como Nietzsche, que a linguagem (e sua variada estrutura) é retórica, não queremos afirmar que o logos argumenta por si mesmo: ele o faz (e é abordado aqui) de forma circunstanciada, 
levando-se em consideração as formações dóxicas e a inserção situacional de seus usuários, o que não desconsidera, amplamente, as convenções de ordem cultural que incidem em toda interação discursiva.

É interessante cogitar, como uma leitura possível, que o manejo e a escolha dos diversos recursos enunciativos - já em si algo retórico -, assim como a forma como se encontram dispostos no discurso, não são procedimentos necessariamente conscientes, mas comportamentos linguísticos já assimilados e naturalizados pelos indivíduos de um grupo, tanto pela absorção das convenções das situações de comunicação (kairos), quanto pela interpelação (inconsciente) dos sujeitos por fatores dóxicos e convenções socioculturais de várias ordens (nomos). Isso quer dizer, também, que a linguagem é primordialmente retórica à revelia do planejamento premeditado e/ou vontade controlada dos seus praticantes, podendo incorrer em efeitos inesperados e em derrapagens imprevistas entre significado e significante. Ainda assim, paradoxalmente, é preciso ficar claro que a linguagem não possui vida própria: seus usos e efeitos, mesmo que de forma inconsciente, estão sempre à mercê de seus usuários. Conforme é organizada por filtros culturais, a força do discurso, portanto, retrata os constituintes do mundo de uma forma (e não de outra), e é justamente nesse retratar os entes de maneiras possivelmente múltiplas que reside sua potência persuasiva.

A partir desse quadro, ou seja, das especulações de Górgias incrementadas por Nietzsche, acreditamos que a conexão (o "elo perdido") entre a Retórica sofística e a AD moderna pode se dar com a retomada da noção de dimensão argumentativa, formulada por Amossy (2010, 2011). A autora nos mostra, mesmo não partindo da leitura dos sofistas, que todo e qualquer discurso é retórico, não havendo mais sentido, assim, a habitual diferenciação entre "Retórica" e "argumentação" (em sua acepção lógica ou racional). A posição assumida, grosso modo, é de que a palavra é necessariamente argumentativa, sendo fruto de um enunciado em situação. Nesse sentido, os enunciados são sempre capazes de interferir nos modos de pensar, agir ou sentir de seus interlocutores, mesmo não havendo uma intenção confessada de persuadir, como em discursos que, pretensamente, pretendem apenas "informar", "descrever" ou "narrar"'.

${ }^{6}$ Note-se que, de acordo com as reflexões da autora, a argumentação não é posta como um "modo de organização do discurso" ou uma "sequência textual" ao lado (e separada) 
De certa forma, essa dimensão argumentativa, da qual nenhum texto poderia escapar, se deve à força da linguagem inteira que, como nos mostrou Górgias e Nietzsche, não atinge jamais as realidades plenamente, mas por perspectivas socioculturais diversas (nomos), o que nos aponta para a incidência de fatores dóxicos nos indivíduos que interagem em "momentos oportunos" (kairos). A conexão, portanto, entre a noção moderna de dimensão argumentativa (AD) e a Retórica sofística de Górgias pode ser arrematada a partir da citação a seguir, de Amossy (2011, p. 132):

o discurso argumentativo não se desenrola no espaço abstrato da lógica pura, mas em uma situação de comunicação em que o locutor apresenta seu ponto de vista na língua natural com todos os seus recursos, que compreendem tanto o uso de conectores ou de dêiticos, quanto a pressuposição e o implícito, as marcas de estereotipia, a ambiguidade, a polissemia, a metáfora, a repetição, o ritmo. É na espessura da língua que se forma e se transmite a argumentação.

Dados esses pressupostos teóricos, a saber, a formulação de uma concepção primordial de Retórica, pautada na espessura e na opacidade da linguagem, assim como a sua conexão com a AD contemporânea, pretendemos demonstrar, a seguir, como esses fundamentos podem funcionar na análise de um texto contemporâneo: a reportagem "Por dentro da máscara dos Black Blocs", publicada no site da Revista Época no dia 15 de novembro de 2013. A análise se concentra em algumas operações linguísticas fundamentais para a projeção retórica de imagens ou representações de mundo - os procedimentos de descrição e narração sistematizados por Charaudeau (2009). Dado o "momento oportuno" (ou kairos) das manifestações de junho de 2013, no Brasil, a questão dos Black Blocs ("blocos de preto") chamou a atenção da grande imprensa, e uma série de reportagens, como a analisada a seguir, surgiram nas mídias naquela conjuntura. A análise busca demonstrar, entre outras coisas, que a

de outras (narrativa, descritiva, enunciativa etc.), como encontramos em vários textos da Linguística Textual e da AD. A argumentação é uma propriedade da linguagem em toda a sua materialidade linguística, sendo parte constitutiva, até mesmo, de estruturas narrativas e descritivas que se pretendem neutras. 
argumentação é um fenômeno presente em todo e qualquer procedimento linguístico, não podendo ser tratada de forma estanque ou separada de seus diversos meios de materialização, como a descrição e a narração.

\section{A projeção retórica dos Black Blocs brasileiros: a (a)versão da revista Época}

A reportagem "Por dentro da máscara dos Black Blocs" foi capa da revista Epoca impressa em 11 de novembro de 2013 (páginas 3642). O texto verbal e não verbal da reportagem foram assinados pelo jornalista investigativo Leonel Rocha, repórter especial da revista. Para fins didáticos, remetemos o leitor ao endereço eletrônico da reportagem, em seu formato on-line ${ }^{7}$ (com páginas não numeradas), e acrescentamos, também, o número das páginas da versão impressa nos trechos ressaltados abaixo durante nossa análise (ROCHA, 2013). Começamos por ressaltar a dimensão narrativa da reportagem para, em seguida, abordar a dimensão descritiva. De acordo com o quadro teórico já esboçado, a Retórica é uma propriedade da linguagem inteira, se a encaramos como um mecanismo simbólico atravessado por parâmetros culturais e situacionais - nomos e kairos -, o que torna impertinente qualquer gesto teórico de separação entre argumentação, descrição, narração ou outro aspecto da materialidade linguageira contextualizada (modalizações, escolhas lexicais, ritmo, entonação etc.). É nesse sentido que a análise abaixo se encontra organizada.

\section{A dimensão narrativo-argumentativa do logos}

A reportagem inicia-se com a narração da saga do jornalista Leonel Rocha, que, para escrever a matéria, teria passado por várias etapas para ser admitido entre os Black Blocs. Iniciemos o nosso percurso com os seguintes fragmentos, nos quais buscaremos sublinhar algumas ações verbais relevantes, assim como algumas expressões adverbiais que lhes colorem o sentido. O procedimento nos permitirá apreender como os referidos manifestantes são representados em termos de actantes narrativos.

Foram necessárias três semanas de negociação até que os ativistas me abrissem seus portões e me permitissem

${ }^{7}$ Disponível em: <http://epoca.globo.com/tempo/noticia/2013/11/bpor-dentro-damascarab-dos-black-blocs.html>. Acesso em: 10 jul. 2015. 
testemunhar seus treinamentos, debates e decisões. Antes, apresentaram exigências e cobraram garantias (p. 37).

No primeiro final de semana de novembro, quando se comemorou o Dia de Finados, pouco mais de 30 pessoas se reuniram nesse sítio para organizar uma nova onda de protestos contra tudo e contra todos - a presidente Dilma Rousseff, políticos em geral, bancos, empresas de transporte, telefonia e comunicação (p. 37).

Os Black Blocs me receberam em seu refúgio. Concederam entrevistas, mas não permitiram filmagens nem o uso de câmeras profissionais. Morelli e Matos aceitaram que eu os fotografasse no sítio com o celular. Escolheram um cenário neutro, de forma a evitar a identificação do local (p. 42).

A meu pedido, fizeram outras imagens após o encontro do fim de semana, para ilustrar esta reportagem. Quem foi ao encontro de Finados ganhou um par de CDs. Eles contêm programas para sabotar redes de computadores de órgãos públicos e empresas privadas (p. 42).

Os trechos acima selecionados representam, em resumo, o início e o fim do percurso narrativo do contato do jornalista Leonel Rocha com os Black Blocs, ou seja, o relato delicado de um processo de negociação com o grupo para se realizarem as entrevistas. A marcação temporal "foram necessárias três semanas de negociação" inicia um encadeamento narrativo que corrobora indiretamente para a projeção retórica de um grupo de difícil acesso, nos moldes de uma organização fechada e obscura.

A escolha lexical dos verbos sublinhados (e seus objetos sintáticos), utilizados pelo autor para se referir aos Black Blocs, reforça esse ponto de vista, estabelecendo um cenário semelhante ao processo de aproximação da imprensa a grupos criminosos ou guerrilheiros: "abriram seus portões", "apresentaram exigências", "cobraram garantias", "não permitiram filmagens", "aceitaram que eu os fotografasse no sítio com o celular", "escolheram um cenário neutro" e "evitar[am] a identificação do local". É interessante observar, ainda, o uso da expressão adverbial "contra tudo e contra todos", conferindo à ação verbal ("organizar uma nova onda de protestos") uma tonalidade de ódio destemperado ao 
mundo, o que corrobora, também, para a construção dos Black Blocs como actantes obscuros. No que se refere ao desenvolvimento da reportagem, o trecho a seguir merece destaque:

o grupo comprou a Kombi que me conduziu e um Jeep Willys com dinheiro que recebeu de entidades nacionais e estrangeiras. Segundo Morelli, desde o início deste ano, já ingressaram nos cofres da Defensoria Social 100 mil euros. Ele afirma que o dinheiro foi repassado pelo Instituto St Quasar, uma ONG ligada a causas ambientais. Morelli também cita entre seus doadores organizações como as suíças La Maison des Associations SocioPolitiques, sediada em Genebra e Les Idées, entidade ligada ao deputado verde Jean Rossiaud. Procurados por Época, ambos negaram ter enviado dinheiro (p. 39).

No trecho anterior, a sequência narrativa busca resposta para uma das perguntas lançadas pela revista Época acerca dos Black Blocs: quem os financia? Os verbos escolhidos para narrar essa situação são herdados (e facilmente associados) do universo obscuro das transações financeiras entre organizações públicas e privadas, no qual se inserem redes de corrupção, favorecimentos e lavagem de dinheiro. Trata-se de um vocabulário próximo dos brasileiros, vide nossos processos históricos: "comprou", "me conduziu", "recebeu", "ingressaram", "afirma”, "foi repassado", "negaram ter enviado" etc. Nesse sentido, a reportagem continua o seu relato:

o encontro de Black Blocs no sítio paulista foi marcado pela improvisação. Na única casa habitável, o telhado exige reforma, e as paredes chamam por pintura. Um gerador a gasolina forneceu energia apenas por algumas horas. A mesa comprida da sala serviu mais para discussão do que para refeição. Os Black Blocs não se reuniram para comer. Ao fazê-lo, não se preocuparam com etiqueta. Saborearam churrasco de carne de segunda e embutidos. Arroz e macarrão foram preparados num fogão de quatro bocas. Para o café da manhã ou para a noite, reservaram biscoitos, café e leite. Banho, só com água de poço, fria. Para beber, levaram garrafas de água mineral. O dinheiro para as compras foi racionado - 
sempre é. Dispunham de uma geladeira e um micro-ondas. Acesso a celular ou internet, só por milagre. Os maços de cigarro foram compartilhados (p. 40).

Ainda sobre as questões levantadas pela revista Época, esse trecho - narrativo e descritivo a um só tempo - ajuda a responder, em parte, à pergunta: quem são eles? Dessa narração/descrição, é possível depreender algo sobre o comportamento dos Black Blocs quando não estão envolvidos em suas ações de manifestação propriamente ditas. O momento recreativo, reservado às refeições, ocorre coletiva e informalmente: "não se preocupam com etiqueta", compram alimentos baratos, de fácil e rápida preparação, o que os configura como actantes precários e desprovidos de bons modos de comportamento. Quanto ao histórico do movimento, a revista também dedica algumas linhas narrativas:

os Black Blocs brasileiros seguem uma onda mundial. São uma manifestação tardia de um fenômeno que tem origem na Alemanha dos anos 1980 e, gradualmente, começou a aparecer nas manifestações de ruas pelo mundo. Primeiro, nos protestos antiglobalização dos anos 1990. Depois, como parte das mobilizações que se seguiram a crise de 2008. Agora, quebram vitrines e enfrentam a polícia no Brasil (p. 42).

Observa-se acima, a partir do uso de encadeadores narrativotemporais ("primeiro", "depois", "agora"), um sucinto panorama sobre a evolução dos Black Blocs: das origens até os momentos atuais, com sutil depreciação do grupo brasileiro que, em sua fase mais recente, "quebra" vitrines e "enfrenta" a polícia. Pode-se cogitar que tal expressão, levantada isoladamente, denota superficialidade intencional em relação ao valor ideológico das ações violentas e do enfrentamento policial. Não se trata, de acordo com os idealizadores da tática, de simplesmente quebrar vitrines e enfrentar a polícia, mas de estratégias de autodefesa e ataques conscientes a bens públicos e privados, símbolos do capitalismo e da má gestão pública (DUPUIS-DÉRI, 2014).

Em síntese, sobre a dimensão argumentativa dessa reportagem, em termos de elementos narrativos, podemos ponderar o seguinte: mesmo que em declarada intenção argumentativa o jornalista, ao fim do 
texto, sustente que não se deve apenas punir os Black Blocs, condenálos ou colocá-los na cadeia ${ }^{8}$, eles são representados, nas entrelinhas do discurso, de forma negativa, como podemos depreender da escolha dos verbos, das expressões adverbiais e dos demais elementos da narrativa. Os "manifestantes de preto" assumem, dessa forma, um papel actancial de malfeitores, criminosos, sabotadores e destruidores, como pressupõe o seguinte trecho, presente no parágrafo final (p. 42):

em toda parte, os Black Blocs são acusados de promover quebra-quebra e espantar das ruas os demais manifestantes. Como uma das missões dos Estados democráticos é combater a violência e preservar a ordem, os Black Blocs frequentemente acabam na cadeia pelos crimes que cometem durante as depredações.

Ora, quem acaba na cadeia por crimes cometidos não pode ser outra coisa, implicitamente, senão um criminoso. Tal representação, a nosso ver, é facilmente deduzível da leitura da reportagem, mesmo que não seja formulada explicitamente. De acordo com o quadro teórico visto anteriormente, podemos já especular, com esse pequeno trecho de análise, que o gênero reportagem conta/aposta naqueles pressupostos filosóficos presentes no antigo polo da physis, isto é, de que a linguagem é capaz de traduzir fielmente seres, fatos e eventos do mundo fenomênico - no caso, os Black Blocs e suas ações -, sendo que, um pouco diferentemente, o que vemos são projeções circunstanciadas da linguagem em sua estrutura retórico-narrativa. Essas projeções não encerram uma "verdade" sobre os mesmos fatos, se temos em mente outras possíveis narrativas sobre os personagens em questão, colocados, muitas vezes, como legítimos “ativistas" (DUPUIS-DÉRI, 2014). Assim, poderíamos encontrar relatos com outras formas de contar o acontecido: ao invés de "quebrar" ou "destruir", nossos actantes, dentro de outro ponto de vista, "socorreriam"

\footnotetext{
${ }^{8}$ Ao fim da reportagem (p. 42), o jornalista afirma: "a cadeia pune a violência e pode coibi-la, mas não ajuda a compreender o que eles querem, quem são, o que pensam, como se organizam - e, principalmente, quem os financia. 'Qualquer um no Brasil que deseje entender o que querem os Black Blocs deveria tentar escutá-los', diz DupuisDéri. É o que ÉPOCA faz nesta reportagem".
} 
vítimas da polícia durante as manifestações, "estariam lutando", mesmo que por métodos violentos, por uma sociedade mais justa. As escolhas linguísticas mostram, dessa forma, que toda palavra é retórica (trata-se de uma escolha), dado que é atravessada por parâmetros ideológicos oriundos das esferas da doxa e do nomos, em um momento oportuno (ou kairos). No item a seguir, através da dimensão descritiva do logos, poderemos compreender melhor quem são os Black Blocs na visão de Época, assim como o que pensam e o que querem.

\section{A dimensão descritivo-argumentativa do logos}

Iniciemos pelo seguinte trecho, em que buscamos sublinhar expressões qualificadoras próprias do ato de descrever (como expressões nominais, adjetivos e advérbios):

nos cartazes pendurados na casa habitável, só havia espaço para teses anarquistas e ambientalistas. Anticapitalistas, os Black Blocs defendem uma genérica "solidariedade humana". A formação intelectual da maioria é quase primitiva. Definem-se como anarquistas porque são, genericamente, contra a repressão do Estado, para eles encarnada pela polícia. A nata do anarquismo é muito citada, mas pouco lida (p. 40).

No trecho, diversos elementos descritivos levantam projeções argumentativas próprias do contexto editorial do jornalista (ou da revista). Inicialmente, o texto parece figurar os Black Blocs como legítimos anarquistas e ambientalistas. Porém, uma das primeiras palavras sublinhadas - "anticapitalistas" - já é grafada em caráter depreciativo, uma vez que a expressão seguinte, "solidariedade humana" (expressão nominal que descreveria a motivação Black Bloc), é destacada entre aspas e, mais ainda, precedida do qualificativo "genérica" (um adjetivo com sutil teor negativo), o que marca uma certa ironia, deboche e questionamento por parte do jornalista. Essas escolhas retóricas parecem nos insinuar, em tom contestador, que estaríamos diante de um grupo organizado por jovens "imaturos", ou melhor, que não sabem sequer o que significaria, genuinamente, a expressão "solidariedade humana". 
Nessa mesma direção, a expressão "a formação intelectual da maioria" estabelece uma designação referencial - o aparato cognitivo do grupo - marcada pelo rótulo descritivo "é quase primitiva". No período seguinte, o advérbio "genericamente" configura-se, também (e novamente), como um julgamento depreciativo da revista sobre a autodenominação feita pelos Black Blocs de "anarquistas" (por serem contra a repressão do Estado encarnada pela polícia). Para materializar esse julgamento, o autor dá sequência a um período explicativo: "a nata do anarquismo é muito citada, mas pouco lida".

Tudo isso vem projetar, indiretamente, um filme em que os personagens principais - os Black Blocs - são caracterizados como manifestantes que expressam as suas convicções por meio de clichês automáticos e com pouco (ou nenhum) conhecimento de causa. Nesse percurso argumentativo, o jornalista conclui a sua progressão textual reforçando o estereótipo de um grupo que diria, em teoria, seguir uma determinada bandeira (ou, no caso, uma tática anarquista contra a repressão violenta do Estado), mas que, na prática, não sabe exatamente o que está dizendo, ou não age, de fato, de acordo com esse fim.

É interessante perceber, a título de contraste, que essa não é a única verdade retórica sobre o grupo. Uma crítica comum aos Black Blocs, inclusive por membros ou partidos de esquerda, incide sobre uma possível confusão teórica e pobreza cognitiva dos ativistas. Porém, segundo Dupuis-Déri (2014, p. 11), "essa forma de crítica é equivocada, uma vez que estima o valor ideológico de ações diretas usando critérios alheios a tais gestos, comparando-os, por exemplo, a tratados de filosofia política e social". Para o estudioso, os Black Blocs não podem ser vinculados a tratados do gênero ou a um determinado perfil ideológico, pois configuram, sobretudo, uma tática, ou seja, uma forma de se comportar nas manifestações, ajudando a dar voz às pessoas que protestam radicalmente contra o sistema, ou a fortalecer a resistência (autodefesa) diante dos ataques violentos da polícia contra a população. Esse ponto de vista diferenciado sobre os Black Blocs, presente no estudo de Dupuis-Déri, nos faz questionar, mais uma vez, a pretensa concepção de linguagem única/infalível oriunda das doutrinas da physis, que parece estar por trás, curiosamente, das expectativas em torno do gênero reportagem contemporâneo. Como vimos em nosso quadro teórico, os fatos e eventos do mundo não possuem, sofistica e gorgianamente, uma essência acessível, isto é, espelhável pelo logos: 
são construções retóricas afetadas por pontos de vista, que buscam, conscientemente ou não, a adesão dos ouvintes/leitores.

Passando adiante, notamos que outra estratégia de descrição recorrente na reportagem é a projeção do todo (o movimento Black Bloc) a partir de suas partes, ou seja, a partir da caracterização dos indivíduos particulares que integrariam o movimento. Esse procedimento metonímico pode ser verificado nas amostragens abaixo, presentes na Revista:

Aos 53 anos, Morelli é o mais velho do grupo. Participou de pastorais católicas de direitos humanos. Integrou o grupo que originou a Comissão Pastoral Operária. Militou com petistas como Luiz Gushiken (1950-2013), ministro da Secretaria de Comunicação Social do governo Lula, e o advogado Luiz Eduardo Greenhalgh. Seu nome aparece em quatro relatórios dos órgãos oficiais de espionagem. Datado de 1987, um documento do extinto Serviço Nacional de Informações (SNI) relaciona Morelli entre punks e anarco-sindicalistas (p. 38).

O mais jovem do grupo, com 17 anos, é um típico punk de periferia paulista, de cabelo moicano. Tenta concluir o ensino médio. Num dos últimos conflitos, foi fotografado quebrando a pontapés uma vidraça de uma agência bancária (p. 38).

Pouco mais velho que ele, um rapaz de óculos, diz ter lido textos anarquistas na internet e não compreender como todos de sua idade não aderiram ao movimento. Morador da periferia paulistana, conta que cresceu assistindo a amigos e vizinhos apanharem da polícia. Nunca votou e afirma que jamais escolheria os candidatos preferidos por seus pais na eleição presidencial de 2010 - Dilma Rousseff e José Serra (p. 39).

O discurso seduz gente como Daniela Ferraz, paulistana criada no complexo de favelas do Capão Redondo. Aos 31 anos, mãe de um filho que mora com o pai, ela cometeu dois assaltos e cumpriu cinco anos de prisão. [...] Ainda cumprindo pena em liberdade, Daniela armouse de paus e pedras para atacar agências bancárias. Agora, é conhecida como Dani, a Pantera dos Black Blocs (p. 41). 
Nos trechos está claro que, a partir dos elementos descritivos destacados (de nomeação e de identificação), os Black Blocs se encontram representados como personagens ligados a um universo de pessoas pobres, de origem operária, de esquerda ("petistas") e, ainda, de famílias desestruturadas ou de jovens com pouco estudo, com tendências até mesmo criminosas ou irresponsáveis ${ }^{9}$. Nota-se, também, que não possuem um emprego formal e, se possuem, a reportagem silencia. No plano éticomoral, pode-se notar uma representação negativa, sobretudo, da ativista feminina - a "Pantera dos Black Blocs" ("mãe de um filho que mora com o pai") -, o que já deslegitima de antemão qualquer argumentação oriunda do grupo, formado que é por pessoas de moral duvidosa e por mães incapazes de cuidar de seus filhos. Como se pode notar, temos aqui o uso do clássico argumento ad hominem, que busca invalidar, falaciosamente, ideias e atitudes mediante ataques pessoais. Em termos de dimensão argumentativa, os trechos acabam se configurando, pode-se sustentar, como um encadeamento de figuras de linguagem - metonímias -, capazes de descrever, retoricamente, o geral pelo particular.

Salienta-se, ainda, que, embora nos ocupemos aqui especificamente da descrição, os elementos narrativos consubstanciados pelos verbos continuam instituindo os Black Blocs como actantes "malfeitores": Morelli, além de ter "militado" com petistas (o que pode ser visto como algo negativo para um certo público), "aparece em quatro relatórios dos órgãos oficiais de espionagem"; o mais jovem do grupo, por sua vez, "foi fotografado quebrando a pontapés uma vidraça de uma agência bancária"; já o rapaz de óculos, "diz ter lido textos anarquistas" e "nunca votou"; Daniela Ferraz, enfim, "cometeu dois assaltos", ainda cumpre pena e "armou-se de paus e pedras para atacar agências bancárias".

Toda a análise aqui empreendida, enfim, parece confirmar o anunciado já no "exórdio" da reportagem: "um sítio a 50 quilômetros de São Paulo abriga um centro de treinamentos para a minoria que adotou o quebra-quebra como forma de manifestação política e ficou conhecida

\footnotetext{
${ }^{9}$ Ressalte-se, nesse mesmo sentido, expressões como "punks e anarcossindicalistas", "o mais jovem do grupo, com 17 anos", "punk de periferia paulista, de cabelo moicano", "morador da periferia paulistana", além de elementos qualificadores ou informativos como "tenta concluir o ensino médio", "diz ter lido textos anarquistas na internet", "cometeu dois assaltos" ou "seu nome aparece em quatro relatórios oficiais de espionagem".
} 
como Black Bloc" (p. 37). Nesse trecho, é importante observar o teor argumentativo da expressão de identificação sublinhada, selecionada cuidadosamente pelo autor para se referir aos Black Blocs. Nesse caso, ao denominar os Black Blocs de "a minoria que adotou o quebra-quebra", a revista estabelece um cenário comparativo que legitima, implicitamente, apenas o grupo de manifestantes ditos pacíficos - "a maioria"-, enquanto outros poucos - os Black Blocs - teriam adotado a barbárie desmedida. Como se pode facilmente deduzir, a expressão "quebra-quebra" nos remete à violência desordenada realizada por vândalos ou arruaceiros, movidos aparentemente por um instinto selvagem indomável, à margem de qualquer processo civilizatório.

Entretanto, essa não seria a única versão existente: por conceito, como já vimos, a "tática" Black Bloc usaria de uma violência consciente contra bens públicos e privados, representativos da má gestão pública e do capitalismo (DUPUIS-DÉRI, 2014). Em outras discursividades, portanto, poderíamos encontrar, sem dificuldades, representações do "bloco de preto" como uma instância "racional", "ativista", "consciente" e, no plano narrativo, "benfeitora" e "socorrista" (por prestar primeiros socorros a manifestantes feridos). Mais uma vez, por tudo isso, retomando o nosso quadro teórico, podemos desvincular da linguagem ou logos o reduto da "verdade absoluta", devolvendo a ele sua natureza essencialmente retórica e humana, justamente por ser afetado pela doxa, pelo nomos e pelo kairos de seus usuários (ou por seus contextos e ideologias, em termos mais modernos). Dessa forma, a constitutividade retórica de todo e qualquer discurso, pautada primordialmente na não transparência da linguagem, nos permite constatar que, sobre todas as coisas, existem sempre pontos de vista em conflito.

Ao fim de nossa rápida análise, é interessante notar, ainda, que, apesar de Leonel Rocha, ao final do texto, sustentar que não se deve apenas punir os Black Blocs, mas, sobretudo, buscar entendêlos, a dimensão argumentativa presente nos mecanismos de narração e descrição os instituem, predominantemente, como uma organização nociva, formada por indivíduos desequilibrados e estranhos ao processo democrático. Dessa forma, como já ressaltamos teoricamente, a análise nos permite constatar que a argumentação não deveria ser definida separadamente da narração, da descrição ou de quaisquer outros mecanismos circunstanciados da estrutura linguística. Feito esse percurso, passemos às nossas últimas palavras. 


\section{Considerações finais}

Neste artigo, buscamos resgatar sucintamente, dada a complexidade do assunto, uma concepção alternativa para a Retórica (ou argumentação) a partir de fontes ainda pouco aproveitadas pela $\mathrm{AD}$, as quais propomos divulgar: uma definição primordial do processo persuasivo presente nas reflexões de Górgias de Leontini, em seu Tratado do não-ente, e desenvolvidas por Nietzsche em seus Escritos sobre Retórica. Essas reflexões nos fazem constatar que a argumentação (ou a Retórica) reside, antes de qualquer coisa, na opacidade e na não transparência do discurso, o que ultrapassa a visualização mecânica de técnicas conscientes e/ou raciocínios prototípicos durante as análises discursivas (embora não se quer, aqui, excluí-los desse processo).

Estando primordialmente nas derrapagens entre significado e significante, afetadas pela doxa e pelas convenções culturais dos sujeitos envolvidos na interação, a Retórica se abre para a força argumentativa da linguagem inteira: dos sufixos e prefixos na formação de palavras, por exemplo, aos elementos narrativos e descritivos do discurso, passando pelo ritmo, pela entonação e demais sutilezas do logos. Buscamos ressaltar, além disso, como esses princípios podem se conectar à noção de dimensão argumentativa, no quadro da $\mathrm{AD}$ de Ruth Amossy, que confere a todo discurso e a quaisquer constituintes linguísticos a propriedade de orientar modos de ver, agir e sentir.

Sendo a argumentação uma propriedade de todo discurso (ou da linguagem inteira), as formulações aqui trazidas contestam as tentativas de definição teórica desse fenômeno como um "modo de organização do discurso" (CHARAUDEAU, 2009) ou "uma sequência textual" ao lado de outras, como as sequências narrativas, descritivas, enunciativas, injuntivas etc. Pensamos, com a análise deste artigo, que a argumentação não pode ser encarada como um procedimento linguageiro específico, como parece ser possível no caso de elementos descritivos e narrativos, mas como uma força que atravessa toda a materialidade textual. Desse modo, buscamos mostrar, com a análise da reportagem "Por dentro da máscara dos Black Blocs", o funcionamento discursivo da descrição e da narração, concluindo pela impossibilidade de tratá-las como uma organização linguageira à parte da argumentação.

Quanto à análise propriamente dita, as questões mais interessantes parecem-nos ser, nestas linhas finais, as seguintes: por 
que nomear um grupo de manifestantes como Black Blocs e disseminar esse "rótulo" somente a partir de 2013, uma vez que a tática "Black Bloc" já teria sido utilizada no Brasil anteriormente? Qual a função retórica dessa nomeação diante das manifestações como um todo? Ora, podemos especular a respeito de uma necessidade política/econômica e uma intenção jornalística balizada por filiações partidárias ou de classe, por exemplo, no intuito de criminalizar movimentos sociais e justificar ações policiais truculentas. Portanto, a partir de representações negativas do grupo como as vistas em Época, muito difundidas pela imprensa corporativa, a expressão Black Bloc pode(ria) funcionar como um grande trunfo retórico para legitimar a condenação de um grupo específico e, principalmente, desmoralizar as manifestações como um todo, de modo, até mesmo, a justificar oficialmente a violência policial nas ruas durante os protestos. Podemos corroborar essa hipótese com um exemplo recente.

No primeiro semestre de 2015, um caso de abuso policial extremo contra manifestantes em greve no Paraná (Curitiba) foi justificado oficialmente pela presença de "Black Blocs" no âmago da manifestação. Entre os dias 27 e 29 de abril de 2015, professores marcharam em carreata após a Justiça paranaense ter concedido uma liminar para que eles e outros servidores tivessem preservado seu direito de entrar nas galerias do parlamento estadual, para acompanhar as votações de um projeto de lei do governo que reduziria pela metade a duração da previdência dos servidores públicos estaduais. Os manifestantes protestaram contra a medida em frente à assembleia, mas não conseguiram liberação para acompanhar a sessão da Comissão de Constituição e Justiça (CCJ) da Alep, na qual foi analisado o projeto de previdência com as emendas propostas pela oposição (VALLE, 2015). Segundo o sindicato dos professores do estado do Paraná, 20 mil pessoas protestavam nesse dia. Além disso,

"a repressão aos servidores começou durante a madrugada", disse Teresa Lemos, secretária estadual do APP Sindicato. $\mathrm{Na}$ ação, a polícia militar guinchou o caminhão de som e ampliou o isolamento em torno da sede do Legislativo estadual. A polícia usou spray de pimenta, bombas de gás e balas de aço revestidas de borracha contra os manifestantes [...]. (GOZZI, 2015). 
Mais de 200 pessoas ficaram feridas, inclusive por ataques de cães da raça pitbull, sendo que oito em estado grave, durante mais um episódio de repressão violenta da polícia do Paraná a professores da rede estadual de ensino, que estavam em greve e acampados no Centro Cívico. Treze pessoas foram presas, segundo a Secretaria de Segurança Pública. A polícia militar foi escalada pelo governador Carlos Alberto Richa (PSDB) para impedir a entrada dos manifestantes na Assembleia onde ocorreu a votação. Segundo uma das várias reportagens sobre o caso (ASSAD, 2015), o governo de Beto Richa justificou as agressões com base na suposta presença de "manifestantes estranhos ao movimento dos servidores estaduais que estavam concentrados em frente à Assembleia Legislativa", principalmente os chamados "militantes black blocs que, infiltrados no movimento, atacaram os soldados da Polícia Militar que protegiam a Assembleia Legislativa". O governador afirmou, ainda, que "a polícia estava lá por determinação do Poder Judiciário para proteger a sede do Poder Legislativo, uma instituição democrática que não pode ser afrontada no seu direito".

Sendo assim, isentando-nos de definir uma "verdade" acerca dos Black Blocs com nossa análise, deixamos aqui a hipótese final de que o uso e a disseminação dessa expressão pode ter funcionado retoricamente para justificar a truculência contra manifestações em geral, ainda mal assimiladas em nosso processo democrático. O jargão oficial "houve repressão violenta porque haviam Black Blocs na manifestação" acabou sendo uma máxima bastante recorrente desde as manifestações de junho de 2013, como nos mostrou o caso do Paraná. Entretanto, o assunto não se esgota em uma análise tão sucinta, restando ainda a necessidade de um estudo mais aprofundado sobre as representações dos Black Blocs na grande imprensa nacional e seus efeitos possíveis.

\section{Referências}

ADRADOS, F. R. La democracia ateniense. Madrid: Alianza, 1975.

AMOSSY, R. L'argumentation dans le discours. Paris: Armand Colin, 2010. . Argumentação e Análise do Discurso: perspectivas teóricas e recortes disciplinares. In: EID\&A - Revista eletrônica de estudos integrados em discurso e argumentação, Ilhéus, n. 1, p. 129-144, 2011. ANSCOMBRE, J. C.; DUCROT, O. L'Argumentation dans la langue. Bruxelles: Mardaga, 1983. 
ARISTÓTELES. Retórica. Lisboa: Imprensa Nacional, 1998.

ASSAD, G. PM reprime protesto de professores em Curitiba e mais de 200 se ferem. El País, Curitiba, 29 abr. 2015. Disponível em: <http:// brasil.elpais.com/brasil/2015/04/29/politica/1430337175_476628.html>. Acesso em 10 jul. 2015.

BRAZIL, V. T. F. O Mo(vi)mento do discurso: entre o tratado sobre a natureza ou sobre o não-ser e o elogio de Helena. Dissertação (Mestrado em Filosofia da Linguagem e do Conhecimento) - Universidade Federal do Ceará, Departamento de Filosofia, Fortaleza, 2012.

CASERTANO, G. Sofista. São Paulo: Paulus, 2010.

CHARAUDEAU, P. Linguagem e discurso: modos de organização. São Paulo: Contexto, 2009.

DUPUIS-DÉRI, F. Black Blocs. São Paulo: Veneta, 2014.

GALINARI, M. M. Górgias e o antigo problema da referência: uma interface entre a Sofística e a Linguística da Enunciação. In: DIAS, L. F. (Org.). Enunciação e materialidade linguística. Belo Horizonte: FALE/ UFMG, 2015, p. 92-100.

GOZZI, R. Professores fazem manifestação e são alvos de repressão da PM do Paraná. Rede Brasil Atual. 28 abr. 2015. Disponível em: $<$ http:// www.redebrasilatual.com.br/trabalho/2015/04/professores-fazemmanifestacao-e-sao-alvos-de-repressao-da-pm-do-parana-2592.html $>$. Acesso em: 10 jul. 2015.

GUTHRIE, W. K. C. Os sofistas. São Paulo: Paulus, 1995.

MARICATO, E. et al. Cidades rebeldes: passe livre e as manifestações que tomaram as ruas do Brasil. São Paulo: Boitempo, 2013.

NIETZSCHE, F. Escritos sobre Retórica. Madrid: Trotta, 2000.

PARMÊNIDES. Da natureza. Tradução, notas e comentários de José Trindade Santos. São Paulo: Loyola, 2013.

PERELMAN, C.; OLBERECHTS-TYTECA, L. Tratado da argumentação: a nova Retórica. São Paulo: Martins Fontes, 2002.

PINTO, M. J. V. A doutrina do logos na sofística. Lisboa: Colibri; Instituto de Filosofia da Linguagem, 2000.

ROCHA, L. Por dentro da máscara dos Black Blocs. Época, n. 807, 11 nov. 2013, p. 36-42. 
ROMEYER-DHERBEY, G. Os sofistas. Lisboa: Edições 70, 1986.

ROMILLY, J. Les grands sophistes dans l'Athènes de Périclès. Paris: Fallois, 1988.

SAITTA, G. L'Illuminismo della Sofistica Greca. Milano: Fratelli Bocca, 1938.

SOUSA, A. A. A.; PINTO, M. J. V. Sofistas: testemunhos e fragmentos. Lisboa: Imprensa Nacional, 2005.

UNTERSTEINER, M. Sofisti: testimonianze e frammenti. Firenze: La Nuova Italia, 1967.

. A obra dos sofistas: uma interpretação filosófica. São Paulo: Paulus, 2012.

VALLE, D. Jornalista paranaense revela detalhes do massacre de 29 de abril. Portal Fórum, 30 abr. 2015. Disponível em: <http://www. revistaforum.com.br/blog/2015/04/jornalista-paranaense-reveladetalhes-do-massacre-de-29-de-abril/>. Acesso em: 10 jul. 2015.

VIGNALI, D. I Sofisti: retori, filosofi ed educatori. Roma: Armando, 2006.

WINDELBAND, W. Alvores do pensamento filosófico grego: período cosmológico. In: VILHENA, V. M. (Org.). Panorama do pensamento filosófico, vol. II. Lisboa: Cosmos, 1958. 